\title{
Technology Antecedents of the Platform-based Ecosystemic Business Models Beyond 5G
}

\author{
Seppo Yrjölä \\ University of Oulu \\ Nokia \\ Oulu, Finland \\ seppo.yrjola@oulu.fi; seppo.yrjola@nokia.com
}

\begin{abstract}
The fifth generation, 5G, mobile communications technologies are expected to transform the future wireless communications services and networks' business models and respective ecosystems. The paper discusses the extended ecosystemic platform architecture for $5 \mathrm{G}$ evolution consisting of components, interfaces, data and algorithms and investigates how this business framework can enable the transformation of the 5G. With roots in economics and engineering, this study looks 5G architecture through the lenses of platform-based ecosystemic business model framework utilizing themes of innovation, openness, complementarity, competition and cooperation, organization and governance, economies of scale and scope, and supply-side, demand-side, two-sided or multisided business models. Based on the timely review of the stateof-the-art studies on the topic in the recent literature and the results of the future-oriented workshop held in 6G Summit 2019, study showed that the transformation from current network-for-connectivity business models towards network-ofservices model builds on platform with data and algorithms.
\end{abstract}

Keywords-business model, ecosystem, platform, 5G, 6G

\section{INTRODUCTION}

Ongoing fifth generation mobile network (5G) deployment is bringing higher speeds, higher capacity, lower latency and greater reliability to applications dependent on connectivity. Compared to date widely implemented $4 \mathrm{G}$ technology originally designed for high-speed mobile broadband, $5 \mathrm{G}$ is a complete redesign of network architecture with the capabilities and agility to support an array of future service opportunities not available in previous generations of network technologies. It will enable networks to go beyond human-to-human interaction, connect further billions of things and reliably control machines in real-time. Moreover, $5 \mathrm{G}$ provides the capability to deliver dynamically end-to-end network slices that dedicate a specific level of performance across the entire network for a given application. Consumer entertainment will be enhanced with super-fast download of high definition video in seconds and new virtual reality experiences. Connectivity for billions of Internet of Things (IoT) will enable e.g., smart factories, where robots, sensors and remotely-located human operators working in synch, and vehicle platooning for huge efficiency gains. [1]

Recent discussions on platform-based ecosystemic business models have started to build a more unified research agenda [2]-[4] for understanding and capturing such business models. With roots in economics and engineering, platform research has an intrinsically dualistic perspective to business [2]. In the economics tradition platforms have been seen as two-sided or multi-sided markets connecting supply and demand, whereas in the engineering tradition they have been seen as modular technological designs for facilitating innovation. There is also a tendency in these literatures to see platforms and ecosystems as intertwined [5], as both traditions acknowledge platforms to be consisting of a complex networked/layered system of modular components and interfaces, the scope and scale of which go beyond the immediate platform actors.

The business model has emerged as a solution to deal with this duality of perspectives, and the increased platformization of businesses is well exhibited in business model discussions. For example, the demand-side business models have come to complement supply-side business model discussions [6], open and mixed business models have come to challenge traditional closed business models [7], and the discussions on ecosystemic business models have fundamentally influenced the way how the environment of the organization is seen [8]. A transformation of business models as well as entire industries from vertical or horizontal towards two-sided and networked was found in [9]. Furthermore, with the emergence of platforms, Iivari et al. [10] defined an "oblique" business model having a focus on value sharing through value cocreation and co-capture, while the traditional vertical controloriented business models have aimed at controlling value creation, and the horizontal business models controlling value capture. In the emerging values sharing oriented ecosystems focusing on co-creation of new services, the key issue according to [7] is the openness of the business model. Particularly, they see the openness of a business model starting from closed and extending toward open edge, open core and open source.

The $5 \mathrm{G}$ technologies are expected to transform the future wireless communications services and networks businesses, business models and respective ecosystems [11][12]. As an emerging field, these $5 \mathrm{G}$ related business models have only been discussed to a limited extent in the literature and platform business models in general have seldom been examined [11][13] in the context of 5G. However, [14] introduced collaborative business models, [15][16] applied the brokerage business model to $5 \mathrm{G}$ businesses and [17] discussed a cloudassisted business model. Beyond technicalities, the models can be seen to represent two basic mobile operator business models, connectivity service provider and its differentiation [18][19].

The application of big data, new algorithms, cloud computing, and next generation wireless connectivity will change the nature of work and the structure of the economy. As the basic connectivity service continues to be commoditized and is under significant pricing pressure, Mobile Network Operators (MNOs) are exploring ways to diversify their businesses. These might involve bundling subscriptions with utility services, providing platforms for ecommerce, increasing focus on the business-to-business market, or emphasizing new areas such as enterprise cloud and the IoT verticals [13]. MNOs all over the world are reinventing their businesses to better position themselves into 
digital transformations trends going beyond the traditional role of communication service provider. That shift requires more focus on innovation, disruption and experimentation to build and execute platforms and ecosystems that drive new business growth and an agile corporate culture [18]. Building on the above discussion, a practical challenge in $5 \mathrm{G}$ business transformation is to discover how future platform business models unfold. Thus, the research question of the paper is as follows: how and why platform-based ecosystemic business models can emerge in the $5 G$ evolution, and what are their technology antecedents?

This research follows the future-oriented action research method [20] and collected and utilized data from the futureoriented workshop held at 6G Wireless Summit in Levi, Finland in 2019. The rest of the paper is organized as follows. Section II presents the research methods and theoretical foundation for the purpose of this paper. Next in Section III $5 \mathrm{G}$ architecture, it's key technology enablers and business models are introduced. Key findings of the study, including the identification of the extended ecosystemic platform architecture for the $5 \mathrm{G}$ business is discussed in Section IV. Conclusions are drawn in Section V.

\section{METHODS}

This section reviews the research methods and theoretical foundation for the purpose of this paper.

\section{A. Future-oriented Action Research}

In this paper, the business model that centers on value creation processes [21] act as a boundary spanning unit of analysis, and qualitative research strategies and methods were applied. The $5 \mathrm{G}$ related business model elements analyzed in this study were created using the anticipatory action learning approach that is a particular action research (AR) method conducted in a future-oriented mode [22]. AR is an iterative and participatory method developed to address the management of change and to develop foresight utilizing cross-disciplinary knowledge, involving practitioners and researchers, and which impacts participants and organizations beyond the research project [23]. The 6G Wireless Summit [24] event was organized by Finnish 6G Flagship Program [25] in Levi, Finland, March 2019. In conjunction with the summit, a 6G white paper workshop was organized with 60 participants including major infrastructure manufacturers, operators, regulators and academia to launch the process for drafting the first $6 \mathrm{G}$ white paper. The target of the workshop was to identify the key drivers, research requirements, challenges and critical research questions related to $5 \mathrm{G}$ evolution and 6G. Workshop was run in 6 groups: use cases, societal and business drivers, radio hardware and spectrum bands, new air-interface, new network technologies and enablers for new services.

\section{B. Platform-based Ecosystemic Business Models}

In contemporary research, business models are seen as a boundary-spanning unit of analysis [26], which connects to three strategic choices by companies [27]; business opportunities explored and exploited [28], value created and captured [29][30], and competitive advantages explored and exploited [31][32]. Furthermore, successful business models are considered to have three strategic consequences: scalability [33][34], replicability [35] and sustainability [36]. Growth of business is frequently connected to scalability and replicability [37][33][38]. The technology, network architecture and service offering can be considered the major constituent parts of a business model [39]. Gatautis [40] found that information and communication technologies-based infrastructure platforms have become the basis for ecosystems allowing to orchestrate and organize activities of many companies. Weil \& Woerner [41] propose four types of business models for the digitalized context: the 1) supplier model that works in a value chain of another company, 2) the multichannel model that makes firms to restructure across several digital and physical touchpoints to serve their customers, the 3) modular model that builds on plug-and-play interfaces to complement their offerings, and 4) the ecosystem model that builds a customer-centric platform to facilitate ecosystemic interaction among the customers. Gawer [2] in turn categorizes platforms as 1) a company and its internal units, i.e., platforms, 2) a network of company and its suppliers, i.e., the supply chain platforms, and 3) an ecosystem keystone actor and its supplement actors in a technology or business ecosystem, i.e., the ecosystem platform.

Ecosystem platform architecture can be defined as a conceptual blueprint that describes how the ecosystem is partitioned into a relatively stable platform, a complementary set of varying modules, and the design rules binding on both [42]-[46]. Decomposition of a platform ecosystem into constituent subsystems minimizes interdependence among the evolution processes within components of the ecosystem, supports change and variation and helps to cope with complexity [47]. Schilling [48] sees platform ecosystem as a complex system composed of interacting subsystems that are always to some degree interdependent and interoperate exclusively using predefined, stable interfaces [49]. Modules can be defined as an add-on software subsystem that connects to the platform to add functionality to the platform [50][45]. Reference [44] defines interfaces as specifications and design rules that describe how the platform and modules interact and exchange information using well-documented, and predefined standards like application programming interfaces (APIs). Baldwin [51] found that modularity decreases coordination and transaction costs across the module boundary while interface standardization decreases asset specificity [48].

Attempts made to look at ecosystemic business models can be found in software, web scale and e-commerce business, cloud, IoT, platform business, and wireless communications contexts. In the digital services domain, everything-as-aservice (XaaS) [52] enables a large number of digital service providers to offer a variety of cloud-based services across the cloud stack layers. The most widely deployed digital as-aservice business models are infrastructure-as-a-service (IaaS), platform-as-a-service (PaaS) and software-as-a-service (SaaS) [53]. A transformation of business models as well as entire industries from vertical or horizontal towards two-sided and networked was found in [9]. Furthermore, with the emergence of platforms, Iivari et al. [10] defined an "oblique" business model having a focus on value sharing through value cocreation and co-capture, while the traditional vertical controloriented business models have aimed at controlling value creation, and the horizontal business models controlling value capture. In these emerging value sharing oriented ecosystems focusing on co-creation of new services, the key issue according to [7] is the openness of the business model. Particularly, they see the openness of a business model starting from closed and extending toward open edge, open core and open source. 


\section{5G ARCHITECTURE, TECHNOLOGY ANTECEDENTS AND BUSINESS MODELS}

This section discusses $5 \mathrm{G}$ architecture and its key technology antecedents through the lenses of platform, ecosystem and business models.

\section{A. $5 G$ Architecture and Key Enabling Technologies}

$5 \mathrm{G}$ is transforming future wireless networks on five streams: 1) Densification by adding millimeter wave (mmWave) small cells in the access network to boost capacity; 2) distribution of radio and core functions, content and services on the edge clouds for pooling gains, low latency, high reliability, security and privacy, and local application; 3) decomposition of network functions to lift scalability, programmable transport mesh that interconnects the distributed datacenter infrastructure; 4) softwarization of the network with advances in analytics and machine learning enables high level of automatization in management and orchestration (MANO); and 5) slicing, utilizing the above capabilities for new as-a-Service business models [56].

A critical aspect of the $5 \mathrm{G}$ network, shifting from the current best effort network connectivity to deterministic connectivity network for service-dominant model, is the ability to create customized network slices, where instances of virtual network resources and applications can be delivered to a new breed of cross-sector services tailored to specific customer needs with service level agreed (SLA) performance on demand as illustrated in Fig. 1. This enables operators to generate new revenues through customized industrial automation and enterprise services while exploiting the benefits of a common network infrastructure. Furthermore, slicing allows operators to provide services by abstracting the slice functionality through open APIs exposure to third party service provide. Application and service providers will be able to use sub-set of the network capabilities in a flexible, configurable and programmable manner, and to use network resources depending on their service preference. Moving from hierarchies to market place for the connectivity and underlying network resources (e.g., spectrum, slices) can more efficiently balance supply and demand, raise the utilization of infrastructure and ultimately maximize economic value within the industry.

The embedding of the cloud in the network edge provides the optimized performance and economics for both the virtualized network functions and any other performance critical enterprise, vertical or web service and can become natural central points, representing the source and destination of much of the demand combined with context analyticenabled optimization capabilities. MNOs are well positioned to transform their networks to fit the requirements since they control the local network connectivity and have significant real estate assets that already are distributed at the edge. Edge cloud use cases considered in $5 \mathrm{G}$ are e.g., cloud radio access network, edge security, network and service automation enhancing the network itself, and industrial automation, massive scale IoT, augmented intelligence with augmented reality/virtual reality [54].

Introduced network elasticity and scalability enable network and resource usage adaptation to needed capacity and service level on demand that improves business agility while reducing capex and opex. Furthermore, software-based network enables efficient infrastructure sharing by different tenants, can open the ecosystem to new players and accelerate time to market by reducing service creation and activation times. The service orchestrator acts as the logical interface between network and business applications through providing abstraction of the network towards applications and interfaces for easy service creation and optimization and expose actionable network insights to application and content providers, enterprises, and industry verticals [12]

Open interfaces to network data enable operators to combine radio data with a variety of other data such as population data, 3D building maps, and activity data from different sources to automatically manage and orchestrate their networks, resources and services across domains and improve their customers' experience. This approach utilizes digital twin concept [55] and leverage artificial intelligence/machine learning (AI/ML) algorithms to simulate network behavior 'in digital' world - based on the $5 \mathrm{G}$ use cases, each with its own capacity, coverage and performance needs. This digital twin approach provides the performance characteristics the network must fulfil. These parameters are used for the end-to-end 5G network design across different domains and simulate its performance. The simulation is then fed back into the use case model in an iterative process that progressively fine-tunes and optimizes the network into a final detailed design with automated recommendation for actions.

Automated security orchestration and management will become crucial in large, cloud-based $5 \mathrm{G}$ mobile network deployments where network functions are no longer bound to specific hardware but may be instantiated on different hardware platforms. End-to-end security needs will have to be managed through a central point of control. This allows the set up and maintenance of effective security mechanisms as the virtualized network is continuously adapting and dynamically reconfiguring for the best performance and user experience. As most network functions are expected to run in network function virtualization (NFV) cloud environments, security mechanisms must ensure a strict isolation between different network slices running on shared infrastructures [56].

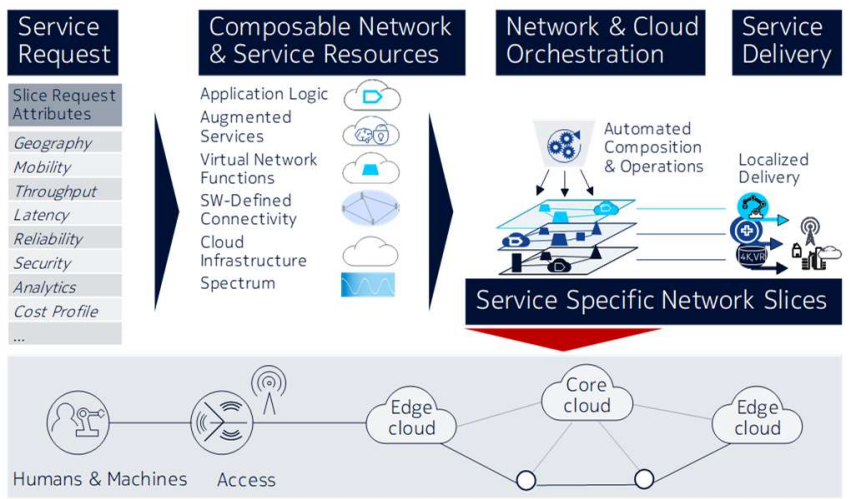

Fig. 1. The $5 \mathrm{G}$ network architecture enables agile service innovations.

\section{B. 5G Business Models}

The switch from one generation of mobile technologies to the next, can compromise the competitive advantage and the relative performance of leading firms [57]. As due to transition from mobile voice services to mobile data services [58], industry convergence and digital disruption in telecommunications industries [59], the value is rapidly migrating across industries and between firms, proactively substituting key elements of the primary business model provides a better fit with the new value landscape [60]. The existing $5 \mathrm{G}$ studies focus on traditional MNO business models 
and discuss $5 \mathrm{G}$ in rather technical and general terms, mostly at the industry level. From technical perspective, focus has been on analyzing the cost, coverage and rollout implications of $5 \mathrm{G}$ networks, e.g., highlighting the impact of spectrum and infrastructure deployment [61], network densification [62], strategies for infrastructure sharing [63], fixed-mobile substitution [64], neutral host deployments of small cells [65], and integration of mmWave and WLAN bands [66].

Transformation of MNOs towards value creation in content and applications and increasing competition with verticals in supplying these utilizing network sharing, multitenancy and wholesale models were found in [67]. Some literature can be found, to discuss the antecedents of business models, i.e., the success factors [68], perspectives to be considered regarding 5G networks [69], and transformation needed to utilize IoT opportunities [70]. Recently, the localized nature of the $5 \mathrm{G}$ services has emerged as a characteristic in these studies. Ahokangas et al. [19] and Matinmikko et al. [71] introduced the micro operator concept, related roles and actors, and business models in $5 \mathrm{G}$, complemented by Matinmikko et al. [72] discussing related regulatory requirements. Four key business opportunities for locally confined micro operators have been presented in [71]: hosting local connectivity to MNOs, offering secure local networks for verticals, providing differentiating local services, and acting as a data operator governing application and user data for various customers. The various core components and roles in mobile communications platform types were characterized by Ballon [73] as enabler, system integrator, neutral or broker models. Furthermore, in addition to telco centric and device-centric model aggregator and service centric model were envisioned [73]-[75]. Context level mobile services' business model designs were studied from service, technology, organizational and financial domain perspectives in [76]. Gonçalves and Ballon [77] analyzed MNOs capabilities to expose network functionalities through adopting web-based SaaS and PaaS models. The impact of the Internet on the telecommunications industry was analyzed in [78] predicting integration between Internet companies and the telecommunication networks, and the Internet companies building networks themselves using unlicensed spectrum technologies or acquiring telecommunication companies. Partnerships and collaboration were found to be an important part of the business models of mobile industry stakeholders [79]. Furthermore, Weber and Scuka [80] and Ghezzi et al. [59] recommended MNOs to move from market protection to specify and manage the implementation of an innovative ecosystem. Yrjölä et al. [13] analyzed novel resource orchestration and configuration-based business models and proposed the novel decentralized marketplace concept for the supply chain of data and virtualized network resources utilizing distributed ledger [81].

\section{Platform-BASEd ECOSYSTEMIC Business MODELS}

The above discussion leads to a number of insights regarding antecedents of the platform-based ecosystemic business models that are next discussed utilizing themes of innovation, openness, complementarity, competition, organization and governance, economies of scale and scope, and finally the type of platform business models enabled.

\section{A. Themes and Antecedents}

\section{1) Innovation}

The engineering approach to platforms highlight innovation as modularity makes managing innovation easier and incremental. Teece [5] discusses profiting from innovation through enabling and general-purpose technologies in the wireless world, raising several concerns for value appropriation and positive spillover effects that are related to enabling and general-purpose technologies. Service oriented architecture, common API framework, slicing and edge cloud if any, can be regarded both as enabling and general-purpose technology, and in due course raise business model related concerns: what kind of business models could enable value creation, capture and sharing from these technologies in practice? Ahokangas et al. [12] found three generic business models for future wireless networks: vertical, horizontal and oblique, each of them having a different logic of innovation.

\section{2) Openness}

Casadesus-Masanell \& Llanes [7] discuss closed, open and mixed business models. They see the openness of a business model starting from closed and extending toward open edge, open core and open source. Openness of business models boils down to discussions on open innovation, and in platform contexts this brings the ecosystem and its stakeholders close. For example, a software-based, serviceoriented cloud native network enables efficient infrastructure and resource sharing by different tenants, can open the ecosystem to new players and accelerate time to market by reducing service creation and activation times. Also, the network and cloud service orchestrator acts as the logical interface between network and business applications through providing abstraction of the network towards applications and interfaces for easy service creation and optimization and expose actionable network insights to application and content providers, enterprises, and industry verticals.

\section{3) Complementarity}

An equally important aspect to innovation and openness is complementarity, that can be related to production, customers, asset prices, inputs, technologies or innovation [5]. This again raises business model related concerns, but more importantly, puts forth the question of the type of platform - whether internal, supply-chain or industry [2] - as different types of platforms may exhibit different types and levels (lightly or loosely coupled) of complementarity. Helfat \& Raubitscheck [4] focus on dynamic and integrative capabilities in platforms and argue that when designing platform business models, on top of the normal business model elements attention should be paid to the core product innovation, functionalities and features, number of sides of the platform, degree of outsourcing as related to complementarity, and governance. The orchestration layer can incorporate an exposure function opening the assets of a network to other service providers like mobile virtual network operators (MVNOs), micro-operators, industry verticals, enterprises and 3rd party applications.

\section{4) Competition and Cooperation}

Competition in platforms may appear at three levels, between platforms, between platform and its partners, and between complementors [5]. Inter-platform competition has been found to result in winner-takes-it-all outcomes in case of large demand, supply-side economies, multi-homing costs, or no niche specialization. But, competition between platforms lead also to increased openness. However, all platform contexts require careful balancing of cooperation and competition at the three identified level. Exposing valuable 
infrastructure and data assets to the developer community through a set of APIs and setting up effective partnerships will allow service providers to grow their businesses by sharing their services with these external partners. Future wireless system architecture enables different levels of exposure to resources and network functions between business actors. Depending on the relationships between business actors and customer there exist different levels of transparency in network slice provisioning and related forms of cooperation models.

\section{5) Organization and Governance}

Gawer [2], de Reuver et al. [3] and Teece [5] all raise the question how to organize and govern platforms. This discussion comes close to the discussion of what types of platforms exist, how to deal with the openness of the interfaces in the platform, what capabilities (i.e., services) are accessible and from where by or through the platform, and whether the governance of the platform is based on ownership (managerial authority), contractual relationships, or ecosystem governance. The standardization of wireless technology has been essential for the global success of the wireless network and the related ecosystem. Standardization ensures global (multi-vendor) interoperability between networks, devices and operators and economies of scale. Furthermore, it minimizes the complexity and thereby reduces the cost of interfaces. Developing a new telecom standard within a standardization organization is based on a consensus of different parties across the ecosystem; vendors, operators, users, interest groups, academia and governments. The key domains of the future wireless system are wider than previous generations, including support for virtualized network function, slicing, converged wireless and wired access, transport, cloud, applications, and orchestration. Diversity in use cases, along with standardization open source platforms are foreseen to become an essential new cross domain collaboration and interoperability tool for the industry and for business agility to provide tailored solution.

\section{6) Economies of Scale and Scope}

The traditional engineering discussion on platforms has been directed to economies of scale in service provisioning, i.e., on the supply-side [5], while in business model discussions attention has been paid to business model scalability [82]. Network effects of the platforms have been seen to increase the value of platforms, but Gawer [2] relates also economies of scope regarding not only to service provisioning, but also innovation, to platforms. Indeed, platformization works together with virtualization that will enable separation of the software from the hardware and offer the possibility to instantiate many functions on a common infrastructure leveraging commodity-of-the-shelf. Introduced network elasticity and scalability enable network and resource usage adaptation to needed capacity and service levels on demand that, in turn, improves business agility.

\section{7) Supply-side, Demand-side, or Multi-sided model}

The demand-side business models have come to complement supply-side business model discussions [6], open and mixed business models have come to challenge traditional closed business models [7], and the discussions on ecosystemic business models have fundamentally influenced the way how the environment of the organization is seen [8]. Traditionally, the wireless networks context has been dominated by supply side business models. In the future, different types of distinct demands will be placed on mobile networks. The consumer of the future will demand contextualized video, smart home services, highly interactive gaming applications and high-resolution immersive content all delivered from the cloud. On the enterprise and industrial front, "physical" industry sectors will be massively transformed by gaining the ability to become automated and to exist independent of physical space and infrastructure essentially to become virtualized. The nature of applications will range from millions of simple low-power sensors to mission-critical operations technologies putting unprecedented demands tailoring and scalability [13]. Different third-party services can seamlessly be integrated and provided to end-users. Thus, the increase in two- or multisided business models is anticipated.

\section{B. $5 G$ Platform Framework}

This study proposes ecosystemic platform architecture for $5 \mathrm{G}$ evolution consisting of components, interfaces, data and algorithms is depicted in Fig. 2.

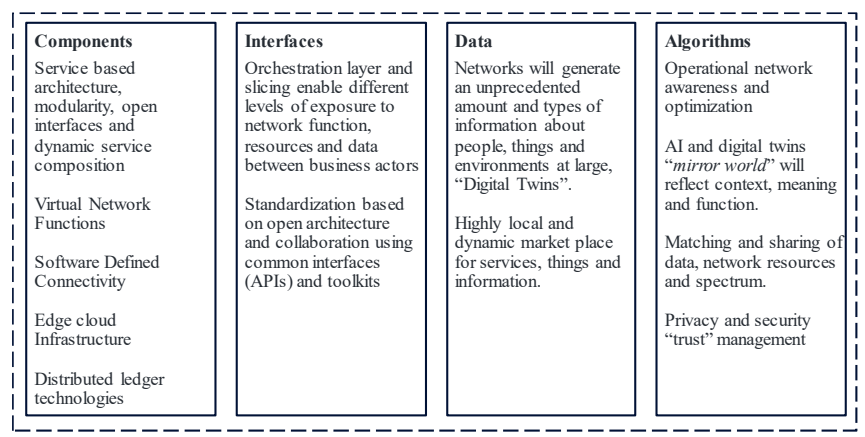

Fig. 2. Network-of-services model builds on platform with data and algorithms.

\section{1) Components}

In connectivity layer, $5 \mathrm{G}$ targets to introduce an increase compared to $4 \mathrm{G}$ in the respective capability by a factor of 10 100 in most of the technology domains. 5G dependable use cases such as wireless factory automation will require ultrahigh reliability, ultra-low latency, high-accuracy inter-device synchronicity, high-resolution localization, etc., corresponding to the current requirements for wired industrial control networks. The future wireless networks must be able to seamlessly interface terrestrial, satellite and airborne networks for the coverage and capacity.

Shorter wavelength and wider available bandwidth will enable increased data rates but also angular and ranging precision for imaging and radar applications for localization, 3D imaging and sensing. Advances in virtualization, automation, and orchestration, combined with the new networking power, will also enable data, intelligence and transactional decision-making to be distributed to the edge of the network. This includes the ability to tie mobility, edge cloud, public/private cloud, and traditional security solutions together into a single, seamless, and integrated system that can follow and protect workflows, applications, and services that need to span the network, from mobile device to data center, regardless of where either is located.

Virtual, augmented, and mixed reality technologies are merging into XR, which encompasses wearable displays and interaction mechanisms that create and maintain perceptual illusions. The users quickly accept an alternative version of reality that enhances their ability to consume media, search the Internet, explore real and virtual worlds, collaborate on work 
projects, connect with family and friends, and engage in restorative activities. Telepresence will be made possible by high resolution imaging and sensing, wearable displays, mobile robots and drones, specialized processors, and nextgeneration wireless networks. Autonomous vehicles for sustainable logistics of humans and shipments are made possible by advances in wireless networks and distributed sensing and AI.

Block chain or distributed ledgers technology is attracting high hopes as AI/ML complementing technologies. Without central authority in a distributed manner, this technology allows storing and sharing information that does not change too often such that the full record of the changes is kept as well. This may give rise to e.g., new ways of organizing data and resource markets or helping to maintain trust in an interoperator setting. The matching and sharing of resources to meet the demands will take place through new kind of activities to ensure inclusion, sustainability and transparency. Ultimately, the emergence and shape of the new wireless ecosystem are dependent on regulations which promote or hinder the developments.

\section{2) Interfaces}

Need for an open architecture and open collaboration using open common interfaces APIs and toolkits were seen essential in every level of the architecture from hardware to services and applications. The complexity both in radio frequency transceivers and in digital signal processing will increase substantially at chip and system levels. This calls for open-source platforms that enable low-level algorithmic development, and possibly go much deeper to specific technologies than any open-source software or hardware seen before. Via softwarization and virtualization of network functions and opening of interfaces, sharing economy concepts will be utilized not only at higher platform business layers but widely in spectrum, network connectivity and data context layers. Changes in the ownership of spectrum access rights, networks, network resources, facilities and customers will result in several different combinations depending on the situation as different facilities have different requirements and infrastructures. New incentives will arise including functioning of the society. The sharing economy will continue to expand and even the nature of transactions will be further disrupted by digital currencies making trust and security essential.

\section{3) Data}

The evolution of networks beyond $5 \mathrm{G}$ will generate an unprecedented amount and types of information about people, things and environments at large. Private information collected from the physical world can be very sensitive and be used against people's, companies and societal interests in many ways. The protection of private and critical information was seen as a key enabler to realize the full potential of $5 \mathrm{G}$ and to make it acceptable to society. The data generated by novel $5 \mathrm{G}$ devices and elements in both public and private networks has value for many societal functions and possibly to other private corporations than the one that collects the data.

Edge cloud computing elements and interfaces enables a local and instant information service e.g., for a fast discovery of people, services, devices, resources and any local information near the user that cannot be collected by centralized search engines. Such edge information service platform could be used e.g., in creation of a highly local and dynamic market place for services, resources and information.
Extreme case for edge computation would be a thin user client, essentially a light low-energy device capable of interacting with human senses or neural system, with all user specific computing occurring in edge cloud.

Data markets offer a natural new business opportunity, where data ownership is a source of value creation and control. Data ownership is evolved from distinct context data towards big data with large volume of detailed data, real-time velocity and high variety in types and sources. The pervasive influence of AI and digital twins will not just reflect what something looks like but its context, meaning and function. We will interact with this "mirror world" [55] manipulate it and experience it like we do the real world. And for the robots this will be the way they see the world. Therefore, creating a big data system that transforms how data are gathered, organized, prioritized, synthesized and distributed can create strong initial controversy, e.g., through raising serious privacy concerns over location and data. Furthermore, how to do business with data itself becomes a key question. The contractual policies between the actors will define the relative strengths of information and data ownership between parties, for example how the trust and ownership will be established in the autonomous smart device and service entities.

\section{4) Algorithms}

Artificial intelligence and machine learning, relying on big data mined to gain information and knowledge, was seen to play a major role from link to system and management and orchestration to business level solutions of future wireless networks to "connect intelligence". Employment of machine learning algorithms was seen essential in addressing the design complexity of radio frequency (RF) systems and improving RF characteristics such as channel bandwidth, antenna sensitivity and spectrum monitoring. More importantly, deep learning-based training models facilitate a better awareness of the operational environment and promise to offer end-to-end learning for creating an optimal radio system. New air interface enablers require extensive usage of ML and AI algorithms to enhance the optimality of the air interface design.

In a future flexible cognitive network with configurable radios, AI and ML can be used in concert with the radio sensing and positioning to learn about the static and dynamic components of the radio environment, to predict link loss events at high frequencies, to proactively decide on optimal handover instances in dense city networks and to find optimal spectrum and radio resource allocation for base stations and users. In the MANO layer, there are intelligence needs in selfconfiguration, optimization and orchestration of virtual resources to meet dynamic content, contextual and event defined needs. Programmable network will utilize a digital twin as an exact digital replica of complex physical assets, processes and systems, providing a detailed understanding of how the real system is behaving and predict what it will do next. Resources and assets needed to meet the versatile needs of the network are then provided by different stakeholder roles providing physical infrastructure (facilities, sites), equipment (devices, networks), data (content, context), under the regulatory framework set by the policy makers. Demands and resources are brought together through the matching/sharing stakeholder roles including different kinds of operators (local or vertical-specific operators, fixed operators, mobile network/satellite operators), resource brokers, and various service/application providers such as trust/security providers. 


\section{CONCLUSION}

This paper aimed at forming a framework for understanding the evolution of future platform-based ecosystemic business models beyond $5 \mathrm{G}$. The paper discusses the extended ecosystemic platform architecture for 5G evolution consisting of components, interfaces, data and algorithms. With roots in economics and engineering, study looks $5 \mathrm{G}$ architecture through the lenses of platform-based business model framework utilizing antecedent themes of innovation, openness, complementarity, competition and cooperation, organization and governance, economies of scale and scope, and type of business models. There is a strong engineering vs. economics duality in platform research; engineering research is focused on components and interfaces aiming at creating economies of scale while the economics research discusses how to connect demand and supply to grow sustainable manner and enter or create new markets. What both streams agree on is that platforms create an ecosystem around them. Furthermore, study shows that the transformation from current network-for-connectivity business models towards network-of-services model builds on platform with data and algorithms. Access to data and data ownership are increasingly the major factors in value creation, and limiting such access is a means of control. Creating a system that transforms how data is collected, shared and analyzed in real time can create strong drivers for future value, introduce novel stakeholder roles, but may also lead to serious privacy and ethical concerns over the location and use of data. The pervasive influence of artificial intelligence will not just reflect what something looks like but also its context, meaning and function, creating "mirror world" of digital twins. Results show that the antecedent themes discussed in this paper are worth further study and real-life use-case studies regarding the business models are needed.

\section{ACKNOWLEDGMENT}

Supported by the Business Finland 5G-VIIMA program. The authors would like to acknowledge the support of the $6 \mathrm{G}$ Flagship project at the University of Oulu.

\section{REFERENCES}

[1] NGMN Alliance, "NGMN 5G White Paper," 2015.

[2] A. Gawer, "Bridging differing perspectives on technological platforms: Toward an integrative framework," Research policy, vol. 43, no. 7, pp. 1239-1249, 2014

[3] M. de Reuver, C. Sørensen, and R. C. Basole, "The digital platform: a research agenda," Journal of Information Technology, vol. 33, no. 2, pp. 124-135, 2017.

[4] C. E. Helfat and R. S. Raubitschek, "Dynamic and integrative capabilities for profiting from innovation in digital platform-based ecosystems," Research Policy, vol. 47, no. 8, pp. 1391-1399, 2018.

[5] D. J. Teece, "Profiting from innovation in the digital economy: Enabling technologies, standards, and licensing models in the wireless world," Research Policy, vol. 47, pp. 1367-1387, 2018

[6] R. L. Priem, M. Wenzel, and J. Koch, "Demand-side strategy and business models: Putting value creation for consumers center stage," Long range planning, vol. 51, no. 1, pp. 22-31, 2018

[7] R. Casadesus-Masanell and G. Llanes, "Mixed source," Management Science, vol. 57, no. 7, pp. 1212-1230, 2011.

[8] B. Demil, X. Lecocq, and V.Warnier, "Business model thinking, business ecosystems and platforms: the new perspective on the environment of the organization," M@ n@ gement, vol. 21, no. 4., 2018.

[9] S. P. Choudary, "Why Business Models Fail: Pipes vs. Platforms," Innovation Insights, Wired Magazine, 2013
[10] M. Iivari, P. Ahokangas, M. Komi, M. Tihinen, and K. Valtanen, "Toward ecosystemic business models in the context of industrial internet," Journal of Business Models, vol. 4, no. 2, pp. 42-59, 2016.

[11] P. Ahokangas, M. Matinmikko-Blue, S. Yrjölä, V. Seppänen, H. Hämmäinen, R. Jurva, and M. Latva-aho, "Business Models for Local 5G Micro Operators," IEEE Dyspan, Seoul, South Korea, 2018.

[12] P. Ahokangas, M. Matinmikko-Blue, S. Yrjölä, V. Seppänen, H. Hämmäinen, R. Jurva, and M. Latva-aho, "Generic Business Models for Local 5G Micro Operators," IEEE TCCN, 2019.

[13] S. Yrjölä, P. Ahokangas, and M. Matinmikko-Blue, "Novel Context and Platform Driven Business Models via 5G Networks," IEEE PIMRC, Genova, Italy, 2018.

[14] J. Noll and M.M. Chowdhury, "5G: Service continuity in heterogeneous environments," Wireless Personal Communications, vol. 57, no. 3, pp. 413-429, 2011.

[15] T. Rasheed et al., "Business models for cooperation," Energy Efficient Smart Phones for 5G Networks, A. Radwan and J. Rodriguez, Eds. Springer International Publishing, pp. 241-267, 2016.

[16] K. Valtanen, J. Backman, and S. Yrjola, "Blockchain Powered Value Creation in the 5G and Smart Grid Use Cases," IEEE Access, vol. 7, no. 1, pp. 25690.

[17] N. Zhang, N. Cheng, A. T. Gamage, K. Zhang, J. W. Mark, and X. Shen, "Cloud assisted HetNets toward 5G wireless networks," IEEE Commun. Mag., vol. 53, no. 6, pp. 59-65, 2015.

[18] P. Ahokangas, M. Matinmikko, S. Yrjolä, H. Okkonen, and T. Casey, "'Simple rules" for mobile network operators' strategic choices in future cognitive spectrum sharing networks," IEEE Wireless Commun., vol. 20, no. 2, pp. 20-26, 2013.

[19] P. Ahokangas, S. Moqaddamerad, M. Matinmikko, A. Abouzeid, I. Atkova, J. Gomes, and M. Iivari, "Future micro operators business models in 5G," The Business \& Management Review, vol. 7, no. 5, pp. 143-149, 2016.

[20] C. Eden and C. Huxham, "Researching organizations using action research," In: Clegg SR, Hardy C, Lawrence TB \& Nord WR (eds) The Sage handbook of organization studies. Sage Publications, London, pp. 389-408, 2006.

[21] R. Amit and C. Zott, "Crafting business architecture: the antecedents of business model design," Strategic Entrepreneurship Journal, vol. 9, pp. 331-350, 2015.

[22] S. Inayatullah, S. (2006). Anticipatory action learning: Theory and practice. Futures, no. 38, pp. 656-666, 2006.

[23] D. Coghlan and T. Brannick, Doing Action Research in your own organization, 3rd edition, Sage, London, 2010.

[24] 6G Summit. Retrieved from www.6gsummit.com

[25] 6G Flagship. Retrieved from www.6gflagship.com

[26] C. Zott, R. Amit, and L. Massa, "The business model: recent developments and future research," Journal of management, vol. 37, no. 4, pp. 1019-1042, 2011.

[27] R. Casadesus-Masanell and J. Ricart, "From strategy to business models and onto tactics," Long range planning, vol. 43, no. 2-3, pp. 195-215, 2010.

[28] C. Zott and R. Amit, "Designing your future business model: an activity system perspective," Long Range Planning, vol. 43, no. 2-3, pp. 216$226,2010$.

[29] N. Foss and T. Saebi, "Fifteen years of research on business model innovation," Journal of Management, vol. 43, no. 1, pp. 200-227, 2017.

[30] R. Amit and X. Han, "Value Creation through Novel Resource Configurations in a Digitally Enabled World," Strateg.Entrep.J., vol. 11, pp. 228-242, 2017.

[31] R. McGrath, "Business models: a discovery driven approach," Long Range Planning, vol. 43, no. 2-3, pp. 247-261, 2010.

[32] L. Massa, C. Tucci, and A. Afuah, "A critical assessment of business model research," Academy of Management Annuals, vol. 11, no. 1, pp. 73-104, 2017

[33] G. Stampfl, R. Prügl, and V. Osterloh, "An explorative model of business model scalability," International Journal of Product Development, vol. 18, no. 3-4, pp. 226-248, 2013.

[34] C. Nielsen and M. Lund, "Building Scalable Business Models," MIT Sloan Management Review, vol. 59, no. 2, pp. 65-69, 2018.

[35] L. Martins, V. Rindova, and B. Greenbaum, "Unlocking the hidden value of concepts: a cognitive approach to business model innovation," Strategic Entrepreneurship Journal, vol. 9, no. 1, pp. 99-117, 2015. 
[36] S. Schaltegger, E. Hansen, and F. Lüdeke-Freun, "Business models for sustainability: origins, present research, and future avenues," Organization \& Environment, vol. 29, no. 1, pp. 3-10, 2016.

[37] J. Aspara, J. Hietanen, and H. Tikkanen, "Business model innovation vs. replication: financial performance implications of strategic emphases," Journal of Strategic Marketing, vol. 18, no. 1, pp. 39-56, 2010.

[38] S. Yrjölä, P. Ahokangas, and M. Matinmikko, "Evaluation of recent spectrum sharing concepts from business model scalability point of view," IEEE DySPAN, Stockholm, 2015.

[39] K. Mason and M. Spring, "The sites and practices of business models," Industrial Marketing Management, vol. 40, pp. 1032-1041, 2011.

[40] R. Gatautis, "The rise of platforms: Business model innovation perspective," Engineering Economics, vol. 28, no. 5, 2017.

[41] P. Weill and S. L. Woerner. "Thriving in an Increasingly Digital Ecosystem, "Sloan Management Review, June 16, 2015

[42] C. Baldwin and J. Woodard, "The Architecture of Platforms: A Unified View In Platforms, Riding in the Open Source Development Model?" Management Science, vol. 52, no. 7, pp. 1116-1127, 2009.

[43] M. Cusumano and A. Gawer, "The elements of platform leadership," MIT Sloan Management Review, vol. 43, no. 3, pp. 51-58, 2002.

[44] M. Katz and C. Shapiro, "Systems Competition and Network Effects," Journal of Economic Perspectives, vol. 8, no. 2, pp. 93-115, 1994.

[45] R. Sanchez and J. Mahoney, "Modularity, Flexibility, and Knowledge Management in Product Contingencies," MIS Quarterly, vol. 23, no. 2, pp. 261-290, 1996.

[46] K. Ulrich, "The Role of Product Architecture in the Manufacturing Firm," Research Policy, vol. 20, no. 2, pp. 180-197, 1995.

[47] H. Simon, "The Architecture of Complexity," Proceedings of the American Philosophical Society, vol. 24 106, no. 6, pp. 467-482, 1962.

[48] M. Schilling, "Toward a General Modular Systems Theory and Its Application to Interfirm Product Organization and Design," Strategic Management Journal, vol. 17, no. 1, pp. 63-76, 2000.

[49] T. Eisenmann, G. Parker, and M. van Alstyne, "Strategies for TwoSided Markets," Harvard, vol. 43, no. 3, pp. 51-58, 2006.

[50] C. Baldwin and K. Clark, "The Architecture of Participation: Does Code Architecture Mitigate Free Riding in the Open Source Development Model?" Management Science, vol. 52, no. 7, pp. 1116$1127,2006$.

[51] C. Baldwin, "Where Do Transactions Come From? Modularity, Transactions, and the Boundaries of Firms," Industrial and Corporate Change, vol. 17, no. 1, pp. 155-195, 2008.

[52] A. Lenk, M. Klems, J. Nimis, S. Tai, T. Sandholm, and P. Alto, "What's Inside the Cloud? An Architectural Map of the Cloud Landscape," ICSE Workshop, CLOUD 2009, IEEE Computer Society, Washington DC, pp. 23-31, 2009.

[53] P. M. Mell and T. Grance, The NIST Definition of Cloud Computing. NIST, (145), Gaithersburg, 2011.

[54] A. Morgado, K. M. S. Huq, S. Mumtaz, and J. Rodriguez, "A survey of $5 \mathrm{G}$ technologies: regulatory, standardization and industrial perspectives," Digital Communications and Networks, vol. 4, no. 2, pp. 87-97, 2018.

[55] D. Gelernter, D. Mirror Worlds: or the Day Software Puts the Universe in a Shoebox...How It Will Happen and What It Will Mean. Oxford University Press, 1993.

[56] J. Ordonez-Lucena, P. Ameigeiras, D. Lopez, J. Ramos-Munoz, J. Lorca, and J. Folgueira, "Network Slicing for $5 \mathrm{G}$ with SDN/NFV: Concepts, Architectures, and Challenges," IEEE Commun.Mag., vol. 55, no. 5, pp. 80-87, 2017.

[57] G. Asimakopoulos and J. Whalley, "Market leadership, technological progress and relative performance in the mobile telecommunications industry," Technological Forecasting and Social Change, vol. 123, pp. 57-67, 2017.

[58] J. Kallio, M. Tinnilä, and A. Tseng, "An international comparison of operator?driven, business models," Business Process Management J., vol. 12 , no. 3, pp. 281-298, 2006.

[59] A. Ghezzi, M. N. Cortimiglia, and A.G. Frank, "Strategy and business model design in dynamic telecommunications industries: A study on Italian mobile network operators," Technological Forecasting and Social Change, vol. 90, no. A, pp. 346-354, 2015.
[60] F. Hacklin, J. Björkdahl, and M. Wallin, "Strategies for business model innovation: How firms reel in migrating value," Long Range Planning, vol. 51, no. 1, pp. 82-110, 2018.

[61] E. Oughton and J.Z. Frias, "The cost, coverage and rollout implications of $5 \mathrm{G}$ infrastructure in Britain," Telecommunications Policy, vol. 42, no. 8, 636-652, 2018.

[62] C. Bouras, A. Kollia, and A. Papazois, "Dense deployments and DAS in 5G: A techno-economic comparison," Wireless Personal Communications, pp. 1-21, 2016.

[63] D. E. Meddour, T. Rasheed, and Y. Gourhant, "On the role of infrastructure sharing for mobile network operators in emerging markets," Computer Networks, vol. 55, no. 7, pp. 1576-1591, 2011.

[64] W. Briglauer, K. Gugler, and A. Haxhimusa, "Facility- and servicebased competition and investment in fixed broadband networks: Lessons from a decade of access regulations in the European Union member states," Telecommunications Policy, vol. 40, no. 8, pp. 729$742,2016$.

[65] F. Fund, S. Shahsavari, S.S. Panwar, E. Erkip, and S. Rangan, "Resource sharing among mmWave cellular service providers in a vertically differentiated duopoly," IEEE International Conference on Communications (ICC), pp. 1-7, 2017.

[66] V. Nikolikj and T. Janevski, "State-of-the-Art business performance evaluation of the advanced wireless heterogeneous networks to be deployed for the 'TERA age'," Wireless Personal Communications, vol. 84, no. 3, pp. 2241-2270, 2015.

[67] M. Cave, "How disruptive is 5G?" Telecommunications Policy, vol. 42, no. 8, pp. 653-658, 2018.

[68] I. Neokosmidis, T. Rokkas, and D. Xydias, "Roadmap to 5G success: Influencing factors and an innovative business model," Internet of Things Business Models, Users, and Networks, pp. 1-8, 2017.

[69] I. P. Chochliouros, A. Kostopoulos, A. S. Spiliopoulou, A. Dardamanis, I. Neokosmidis, T. Rokkas, and L. Goratti, "Business and market perspectives in $5 \mathrm{G}$ networks," In Internet of Things Business Models, Users, and Networks, pp. 1-6, 2017.

[70] M. R. Palattella et al., "Internet of Things in the 5G Era: Enablers, Architecture, and Business Models," IEEE Journal on Selected Areas in Communications, vol. 34, no. 3, pp. 510-527, 2016.

[71] M. Matinmikko, M. Latva-aho, P. Ahokangas, S. Yrjölä, and T. Koivumäki, "Micro operators to boost local service delivery in $5 \mathrm{G}, "$ Wireless Personal Communications, no. 95, pp. 69-82, 2017.

[72] M. Matinmikko, M. Latva-aho, P. Ahokangas, and V. Seppänen, "On regulations for 5G: Micro licensing for locally operated networks," Telecommunications Policy, vol. 42, no. 8, pp. 622-635, 2018.

[73] P. Ballon, "The Platformisation of the European Mobile Industry," Comms \& Strategies, vol. 75, no. 15, 2009.

[74] Y. F. Kuoa and C. W. Yub, "3G telecommunication operators' challenges and roles: A perspective of mobile commerce value chain," Technovation, no. 26, pp. 1347-1356, 2006.

[75] J. Zhang and X. J. Liang, "Business ecosystem strategies of mobile network operators in the $3 \mathrm{G}$ era: The case of China Mobile," Telecommunications Policy, vol. 35, no. 2, 2011.

[76] M. de Reuver and T. Haaker, "Designing viable business models for context-aware mobile services," Telematics and Informatics, no. 26, pp. 240-248, 2009.

[77] V. Gonçalves and P. Ballon, "Adding value to the network: Mobile operators' experiments with Software-as-a-Service and Platform-as-aService models," Telematics and Informatics, Vol. 28, No. 1, pp. 1221, 2011.

[78] R. Feasey, "Confusion, denial and anger: The response of the telecommunications industry to the challenge of the Internet," Telecommunications Policy, vol. 39, no. 6, pp. 444-449, 2015.

[79] G. Camponovo and Y. Pigneur, "Business model analysis applied to mobile business," Proceedings of the 5th International Conference on Enterprise Information Systems, pp. 23-26, 2003.

[80] A. Weber and D. Scuka, "Operators at crossroads: Market protection or innovation?" Telecommunications Policy, vol. 40, no. 4, pp. 368377, 2016.

[81] S. Yrjölä, "Decentralized 6G Business Models," 6G Wireless Summit, Levi, Finland, 2019.

[82] M. Lund and C. Nielsen, "The Concept of Business Model Scalability," Journal of Business Models, vol. 6, no. 1, pp. 1-18, 2018. 